\title{
Posterior omuz instabilitesi
}

\author{
Posterior shoulder instability \\ Mehmet Demirtaş ${ }^{1}$, Mehmet Armangil ${ }^{1}$, Uğur Bezirgan² \\ ${ }^{1}$ Ankara Üniversitesi Tıp Fakültesi, Ortopedi ve Travmatoloji Anabilim Dalı, Ankara \\ ${ }^{2}$ Diyarbakır Devlet Hastanesi Ortopedi ve Travmatoloji Bölümü, Diyarbakır
}

\begin{abstract}
Glenohumeral eklemin posterior instabilitesinin tanı ve tedavisi ortopedik cerrahlar için sorun oluşturmaya devam etmektedir. Egzersizler, nonsteroid antiinflamatuar tedaviler ve aktivite kısıtlaması gibi konservatif önlemlere rağmen sıklıkla bir ilerleme kaydedilse bileher hastada başarılı olunamamaktadır. Özellikle genel ligamentöz laksitesi olan ve tekrarlayan mikrotravmaya sekonder instabilite gelişen hastalar agresif egzersiz programına yanıt verir. Tekrarlayan makrotravmatik instabilitesi olan hastalara egzersiz programları pek yardımcı olmaz, buna rağmen başlangıçta her zaman denenmelidir. Eğer semptomlar kalıcı olursa cerrahi tedavi gerekebilir. Teknik ya da teknik kombinasyonların seçimi mevcut patolojiye, instabilitenin derecesi ve doğasına, hastanın aktivite seviyesi baz alınarak yapılmalıdır. Artroskopik teknikler umut vericidir ve sıklıkla kulanılmaktadır. Ancak, teknik olarak zordur ve her hastada iyi sonuç vermeyebilir. İlave açık stabilizasyon teknikleri gerekebilir.
\end{abstract}

Anahtar sözcükler: omuz eklemi; eklem instabilitesi; tedavi
The management of recurrent posterior shoulder instability can be challenging. Although nonoperative measures, including exercises, nonsteroid antiinflamatory medications and activity restrictions often lead to some improvement, problems persist. Most patients with posterior instability will respond to an agressive exercise program, particularly patients with generalised ligamentous laxity and instability occcuring secondary to repetitive microtrauma. Patients who suffer repetitive macrotraumatic instability are less likely to be aided by an exercise program, although one should always be instituted initially. If patients' symptoms are disabling, surgical intervention is indicated. The choice of technique or combination of techniques should be based on present pathology, the degree and nature of the instability and activity level of the patient. Artroscopic techniques have recently demonstrated promise and are commonly used by the authors. Although these techniques are demanding, they are not always the best choice. Supplemental open stabilisation techniques are occasionally required.

Key words: shoulder joint; joint instability; treatment

Atravmatik veya tekrarlayan mikrotravmalara bağlı olarak kazanılmış tekrarlayan posterior subluksasyonlar travmatik posterior çıkıklara göre çok daha sıktır. $\mathrm{Bu}$ instabilite şekilleri dikkatlice değerlendirilerek; tek yöne, iki yöne veya çok yöne olarak sınıflandırılmalı ve çıkığın yönü ile semptomatik subluksasyonlar ayrılmalıdır. ${ }^{[2]}$ Posterior instabilite ile sonuçlanan tekrarlayan aşırı kullanım ve mikrotravma hasarı; baş üstü sporlarda ve ağırlık kaldırma gibi posterior kapsüle tekrarlayan travmalar sonucu ortaya çıkmaktadır. Tekrarlayan posterior subluksasyon tanısı konulan bir grup hastada semptomların başlangıcı hiçbir aktivite veya travmaya bağlanamaz. Bu gibi hastaların çoğunda genel ligamentöz laksite vardır. Glenohumeral instabilite cerrahisinde başarılı olabilmek için, instabilitenin cerrahi ile

- Iletişim adresi: Prof. Dr. Mehmet Demirtaş, İran Caddesi No:15/6 Kavaklıdere, Ankara

Tel: 0312 - 5082617 e-posta: mdemir@medicine.ankara.edu.tr

- Geliș tarihi: 15 Haziran 2013 Kabul tarihi: 25 Ekim 2013 
düzeltilebilen mekanik faktörlere bağlı olması gereklidir. ${ }^{[3]}$ Posterior instabilitede birçok faktör eşzamanlı olarak bulunabilirken tedavi planlanırken bu faktörler ortaya konmalıdır.

Sadece kas kasılması ile omuzunu sublukse edebilen hastalarda büyük olasılıkla psikolojik köken ve sekonder kazanç söz konusudur. Bu hastalar omuzları abduksiyonda iken sadece iç rotatorlarını kullanarak omuzlarını posteriora sublukse edebilirler. Başarı şansı düşük olduğu için bu gibi hastalar nadiren cerrahi olarak tedavi edilmelidirler. ${ }^{[4,5]}$ Geçmişte glenoid tipinin posterior instabilitede etkili olduğu düşünülüyordu. Ancak, sadece ciddi konjenital displazi veya kemik yapısının atravmatik bozulması durumlarında glenoid tipinin posterior instabiliteye etkili olduğu düşünülmektedir. ${ }^{[6]}$

Rekürren posterior dislokasyonun semptomları diğer omuz problemlerine benzemektedir; bu yüzden kesin tanıyı koymak biraz güçtür. En sık görülen şikayet, çoğu omuz problemlerinde olduğu gibi ağrıdır. Ağrı, humerus başının glenoid köşesine yüklenmesine veya rotator manşetin humerus başını glenoidde tutmak için üzerine binen aşırı strese bağlıdır. Posterior subluksasyonu olan hastalar omuz belli pozisyonlara yer değiştirirken takılma hissi veya krepitasyon hissettiklerini anlatırlar. Pek çok hasta zaman ilerledikçe omuzlarının eklemden çıkacakmış gibi hissettiklerini ve aynı zamanda instabilite sıklığında bir artış da gözlemlediklerini söylerler. ${ }^{[7]}$
Fizik muayenede bazı hastalarda kol $90^{\circ}$ abduksiyonda iken iç rotasyon kaybı tespit edilebilir. Posterior stres testi hasta supin pozisyonda, kol $90^{\circ}$ abduksiyon ve nötral rotasyonda iken yapılır (Şekil 1 ). Humerus başının glenoidde translasyonu her iki omuzda dikkatlice test edilir ve derecelendirilir. Anterior instabilitenin aksine provokatif pozisyonda korkutma testi çok sık olmayan bir bulgudur. Bu bulgu sıklıkla omzuna akut indirekt travma alanlarda gözlenir. Stres testleri ayrıca çok yönlü instabiliteyi değerlendirmek üzere anterior ve inferior yönlerde de uygulanmalıdır. Posterior subluksasyonu çok yönlü instabiliteden ayıran tanısal kriterler; semptomların oluştuğu kol pozisyonu, stres testinde inferior translasyon derecesi ya da hastanın istemli olarak posterior instabiliteyi gösterip gösteremediğidir. Bu ayrımın yapılması, eğer cerrahi düşünülüyorsa, cerrahi yaklaşımın seçimi açısından önemlidir. ${ }^{[7]}$

Eğer hikaye ve muayene, rekürren posterior subluksasyon ile uyumlu ise omuza posterior yaklaşımı kullanarak inferior glenohumeral ligament (IGHL) ve posterior kapsülün gerginliğini yeniden ayarlanabilir. İkinci instabilite yönü olarak inferior translasyonun derecesi sulkus işareti 3+ olmadıkça yaklaşımı değiştirmek gerekli değilidir. Bu hastalarda bazı cerrahlar inferior translasyonu azaltmak için önden cerrahi yaklaşımla rotator aralığın kapatılmasını takiben posterior kapsül onarımını uygulamışlardır. ${ }^{[8,9]}$ Omuza iki yönden

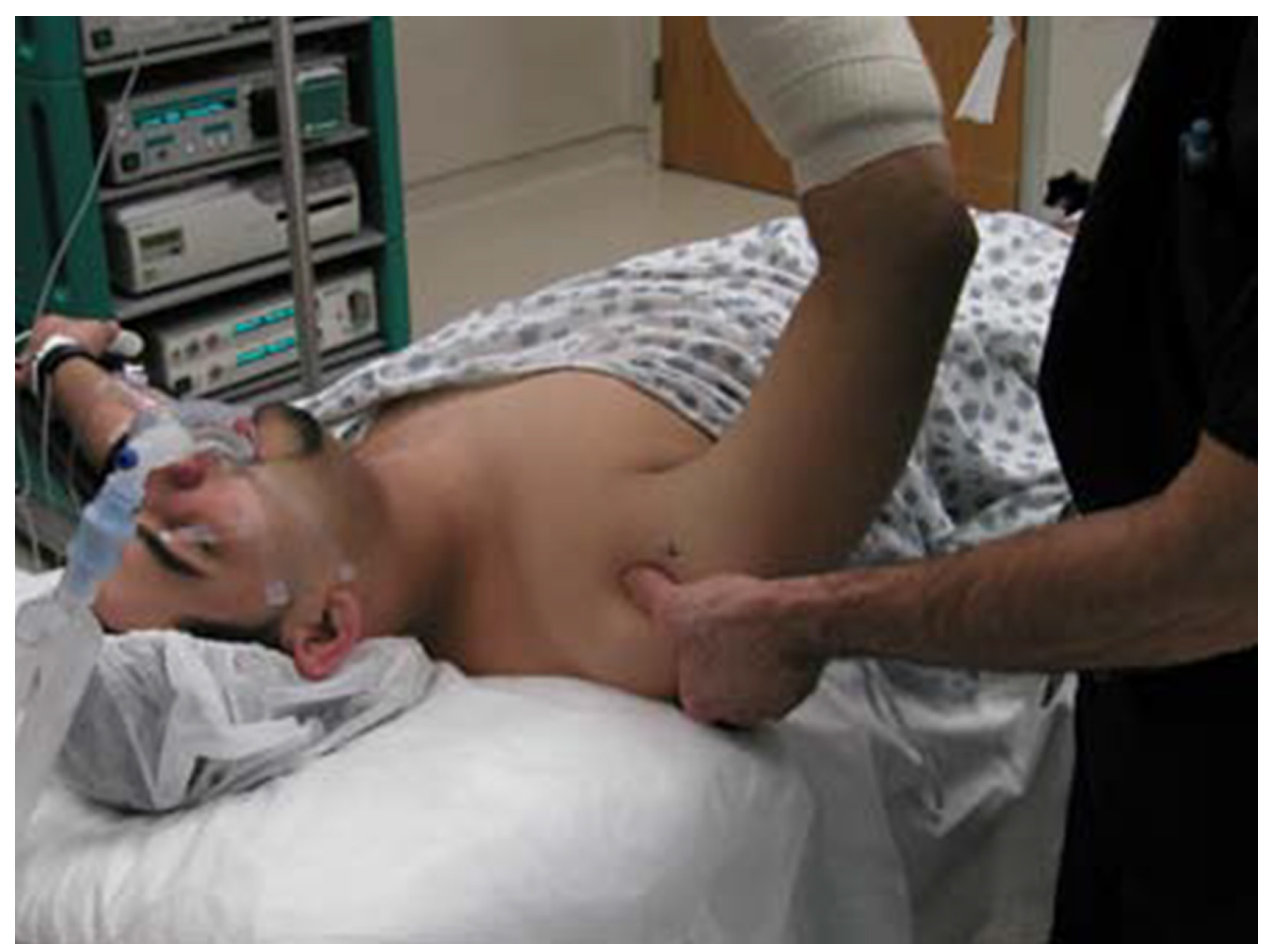

Şekil 1. Kol abdüksiyonda posteriora zorlama ile humerus başı posteriora yer değiştirir. 
yaklaşımın gerekli olup olmadığı ya da eklem stabilitesine anlamlı bir katkısının olup olmadığı açık değildir.

Radyografik değerlendirmede iç rotasyonda A-P grafi, West Point aksiller grafi ve Stryker notch grafisini içeren tipik instabilite serileri olmalıdır. Omuz aksiller görüntüde posteriora sublukse olmadıkça radyografiler sıklıkla bize bir şey söylemez. Geçmişte, glenoid kenar ve kapsülün posterior görünümünde $\% 20$ kalsifikasyon insidansı saptanmıştır. BT, omuzda glenoid ve humerus başının versiyonunu tayin etmede faydalıdır. ${ }^{[10]}$ Artrografi ve Artro MR labral ve kapsüler patolojiyi gösterdiği için en güvenilir tanısal yöntemdir (Şekil 2). Artroskopik değerlendirme kıkırdak ve diğer patolojileri gösterdiği için en güvenilir tanısal araçtır.

\section{KONSERVATIF TEDAVi}

Posterior omuz instabilitesinde ilk tedavi konservatif tedavi olmalıdır. Konservatif tedavide amaç, hastanın çıkığa neden olacak aktivitelerden kaçınması ve posterior subluksasyona sebep olacak istemli hareketlerden kaçınmasını öğretmektir. Tedavinin esas amacı dış rotatorların özelliklerde infraspinatus kasının rehabilitasyonudur. Kasların kuvvetlendirilmesi posterior instabilitede anteriora kıyasla daha etkindir fakat her hastada başarı sağlanamamaktadır. Bununla birlikte, normal hareket açıklığı da elde edilmelidir. ${ }^{[11]}$
Özellikle genel ligament laksitesi ve tekrarlayan mikrotravmalar sonucu gelişen çoğu omuz instabilitelerinde hastalar yoğun egzersiz programından çok faydalanır. Baş üstü sporu ile uğraşan atletlerde bilgili bir antrenörün gözlemi ve eğitimi ile instabilite sıklığı azaltılabilir. ${ }^{[12]}$

Eğer 4-6 aylık uygun rehabilitasyon programı ile başarı sağlanamaz ise cerrahi müdahale endike olabilir. Eğer ağrı ve instabilite etkilenen omuzun günlük hayatı engelliyor veya hastanın omzundan beklentisini karşılamasına engel oluyorsa cerrahi uygulanmalıdır. ${ }^{[13]}$

\section{CERRAHI TEDAVi}

Yillar boyunca posterior instabilitenin tedavisinde 'Reverse Bankart' ve 'Putti-Platt' gibi yumuşak doku ameliyatları, kas transferleri ve kapsülorafi, kemik blokları ve glenoid osteotomileri gibi çok çeşitli ameliyatlar önerilmiştir. 1984'te Hawkins ve arkadaşları, tekrarlayan posterior omuz instabilitesi için uygulanan çeşitli posterior stabilizasyon prosedürleri ile $\% 50$ başarısızlık oranı bildirmişlerdir. ${ }^{[14]}$ Tibone ve Ting, $U$ çivisi kullanarak kapsülorafi ile tedavi edilen atletlerde \%40 başarısızık oranı bildirmişlerdir. ${ }^{[15]}$ Bigliani ve arkadaşları, posterior kapsüler kaydırma prosedürü sonrası minimum 2 yıl takipli 35 hastanın 28'inde (\%80) iyi ve mükemmel sonuç bildirmişlerdir. Kötü

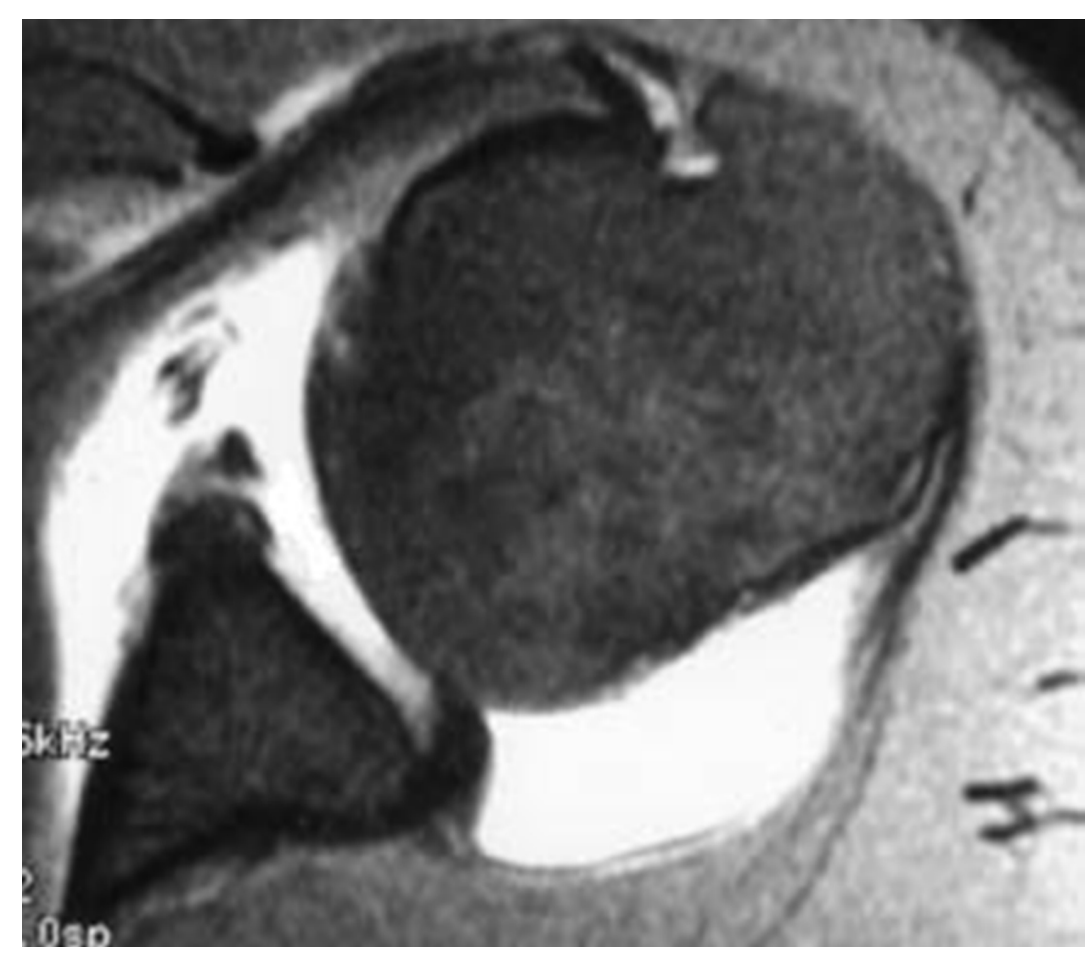

Şekil 2. Genişlemiş kapsül labrum kemikten ayrılmış Artro MR görüntü. 
sonuçlanan 7 omuzun 6'sında önceden stabilizasyon prosedürü uygulanmıştır. illk tedavisi posterior kapsüler kaydırma olan 24 omuzun 23'ünde (\%96) iyi ve mükemmel sonuç elde etmişlerdir. ${ }^{[9,16]}$ Hawkins ve Janda posterior kapsülotendinöz germe ameliyatı uygulanan 14 hastanın ortalama 44 aylık takiplerinde hiçbir tekrarlayan posterior instabilite ile karşılaşmamışlar ve tüm hastalarında başparmaklarını T8 vertebra seviyesine dokunabilecek kadar yeterli seviyede iç rotasyon elde ettiklerini bildirmişlerdir. ${ }^{[14]}$

Genel olarak tekrarlayan travmatik posterior dislokasyonlu hastalarda posterior instabilite tedavisine yönelik olarak uygulanan cerrahi teknik ile iyi sonuç elde edilmiştir. Bununla birlikte daha sık karşılaşılan posterior instabilitenin eklem hareket açıklıklarında aynı sonuçlar elde edilememiştir.

Saf travmatik tekrarlayan posterior omuz çıkığı oldukça nadirdir; çoğu posterior instabiliteler çok yönlüdür. Sık tekrarlamadığı, belirgin sakatlık yaratmadığı ve konservatif tedavi başarısız kalmadığı sürece posterior instabilitenin atravmatik tipinde cerrahi müdahale önerilmemektedir.

\section{Posterior kapsüler tendon gerginlik ayarlanması tekniği}

Hawkins ve Janda ${ }^{[14]}$ tarafindan tanımlanan teknik en iyi işçiler veya temas sporu ile uğraşan atletler için uygulanabilir (Şekil 2). Temel olarak ters Putti-Platt ameliyatının bir modifikasyonudur. Her ne kadar prosedürün iç rotasyonda belirgin kayıp yaratmadığını buldularsa da bu teknik rutin olarak baş üstü sporla uğraşan atletlerde önerilmemektedir.

Tibone ve Bradley $U$ çivisi ile yapılan kapsülorafilerdeki kötü sonuçları (\%40) nedeniyle infraspinatus ve teres minor arsından girilerek posterior kapsüler kaydırma tekniğinin bir varyasyonunu önermektedirler. ${ }^{[12]}$

\section{Neer'in posterior girişim ile inferior kapsüler kaydırma yaklaşımı}

Bu teknikte posterior kapsül longitudinal olarak kesilir ve olabildiğince inferior ve anteriordan humerus başı boyunca kapsüler yapışma gevşetilir (Şekil 3). Superior kapsül inferiora, inferior kapsül superiora doğru gerdirilir. İnfraspinatus kası kesilerek ve üst üste getirilerek kısaltılır, posterior kapsüle daha fazla destek olması sağlanır. Bu prosedür aksiler bölgedeki kapsül gevşekliğini kapatır ve fazlalığı ortadan kaldırır (Şekil 4). Bu ve diğer kapsüler kaydırma teknikleri, gerçek travmatik tekrarlayan posterior çıkık olmayan posterior subluksasyonda kullanılır. ${ }^{[5,8,9,15]}$

\section{Kapsüler kaydırma ile birlikte posterior kemik blok}

Kemiksel glenoid defekti olmayan, dayanıklı posterior kapsülü ve infraspinatus tendonu bulunan hastalarda yumuşak doku tamiri tek başına yeterlidir. Bigliani ve arkadaşları, glenoid hipoplazi belirgin ise veya revizyon ameliyatlarında yetersiz posterior yumuşak doku bulunduğu durumlarda spina skapuladan veya iliak kanattan alınan posterior kemik blok ile kapsüler kaydırmayı önermişlerdir (Şekil 5). ${ }^{16]}$ Kemik grefti güvenli bir şekilde skapula boynuna tespit edilmelidir. Greft ekstrakapsüler olarak 6-8 milimetre kadar skapulanın lateral kenarından taşmalıdır. Bloğun ekstrakapsüler olması ve humerus başını belirgin olarak sıkıştırmaması çok önemlidir. Kemik grefti uygulaması nadiren gerekli olur ve sadece belirgin kemik-yumuşak doku defekti bulunan hastalarda kullanılmalıdır. ${ }^{[16,17]}$

\section{Posterior glenoid osteotomisi ile beraber kapsüler kaydırma rekonstrüksiyonu}

Boyd ve Sisk, posterior kapsülün güçlendirilmesi için biceps tendonunun uzun başının transferi ile beraber posterior kapsülorafiyi tarif etmişlerdir. ${ }^{[18]} \mathrm{Her}$ ne kadar bu prosedür ile tatmin edici sonuçlar elde etseler de biceps labral kompleksin ayrılması önerilmemektedir. Aynı şekilde Scott tarafından tarif edilen posterior glenoplasti de nadiren endikedir. Ancak tomografi ile doğrulanmış ciddi gelişimsel veya travmatik glenoid displazilerinde kullanılabilir. Bu prosedür ile \%53 (Norwood ve Terry) ve \%41 (Hawkins ve arkadaşları) yüksek nüks oranları bildirilmiştir. Hawkins ve arkadaşları bu prosedür sonrasında glenoid avasküler nekrozu ve glenohumeral eklemde osteoartrit gibi komplikasyonları içeren \%29 oranında komplikasyon bildirmişlerdir. ${ }^{[19]}$ Şimdi daha basit ancak glenoid osteotomi kullanarak benzer bir prosedür, Rockwood tarafindan travmatik veya konjenital ciddi glenoid displazilerinde tercih edilmektedir. ${ }^{[19]}$

\section{McLaughlin tekniği}

Büyük anterior medial Hill-Sachs lezyonunun eşlik ettiği tekrarlayan posterior çıkıklar için McLaughlin, subskapularis tendonunun defektif bölgeye naklini tanımlamıştır. ${ }^{[20]}$ Neer ve Foster ise subskapularis tendonunun tuberisitas minor ile birlikte defektif bölgeye nakli ve bir adet vida ile tespitini tanımlamışlardır. \%20-25 oranında eklem yüzeyinin tutulumu ile beraber nadir ters Hill-Sachs lezyonlarında bu teknik ile tatmin edici sonuçlar elde edildiği gösterilmiştir.[21]

\section{Artroskopinin rolü}

Glenohumeral eklemin artroskopisi birkaç nedenden ötürü subluksasyonu olan hastalarda endikedir. 


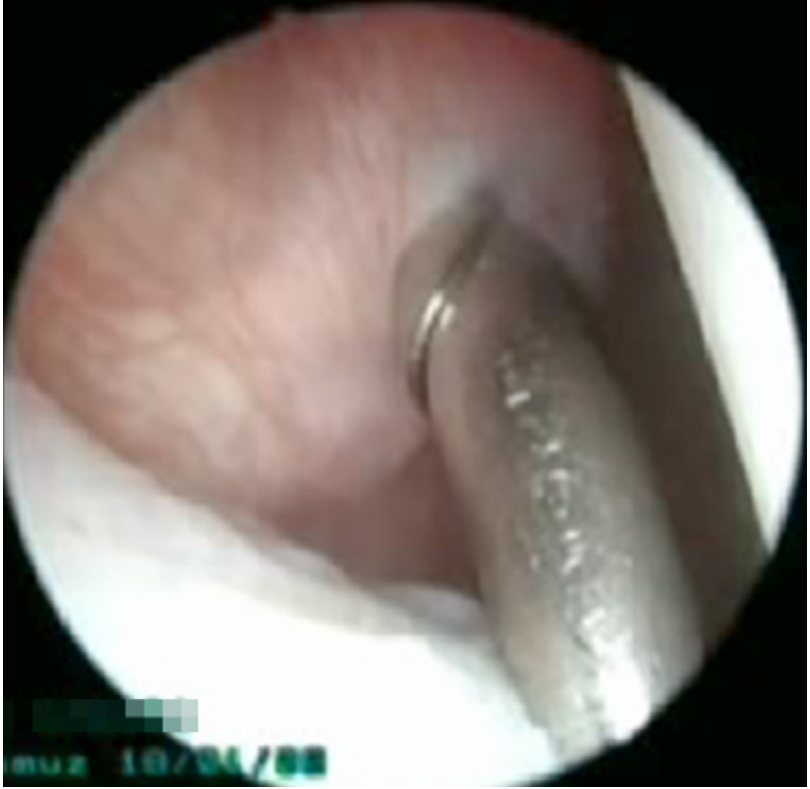

Şekil 3. Kapsül muayenesi.

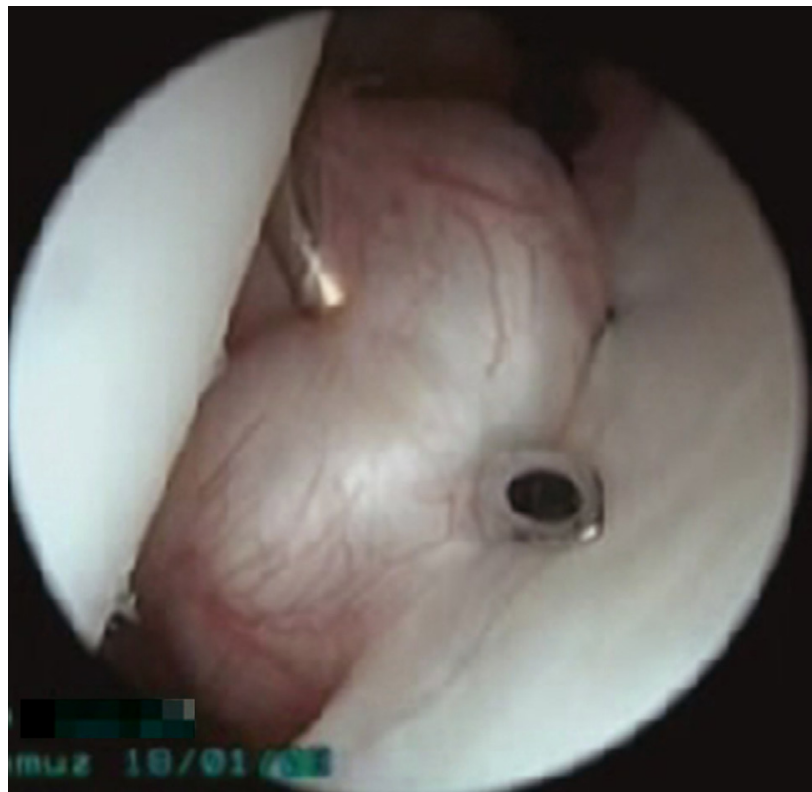

Şekil 5. Sütür taşıyıcı ile anterior kapsül dikişi.

Artroskopi cerrahıneklem içi kapsüloligamentöz anatomiyi değerlendirmesiyle birlikte aşırı anterior translasyonu ekarte etmesine yardımcıdır. Posterior kapsülolabral ayrışma tanımlandıysa da artroskopik tamir denenmelidir. ${ }^{[22]}$

Yeni bir ilgi alanı kapsül yapısındaki kollajeni kısaltarak ve kapsüler hacmi düşürerek etki eden lazer veya termal tedavilerdir. Ancak bu tedavilerin kıkırdak hasarına yol açtığı kanıtlandığı için termal büzüştürme artık kullanılmamaktadır. ${ }^{[23]}$

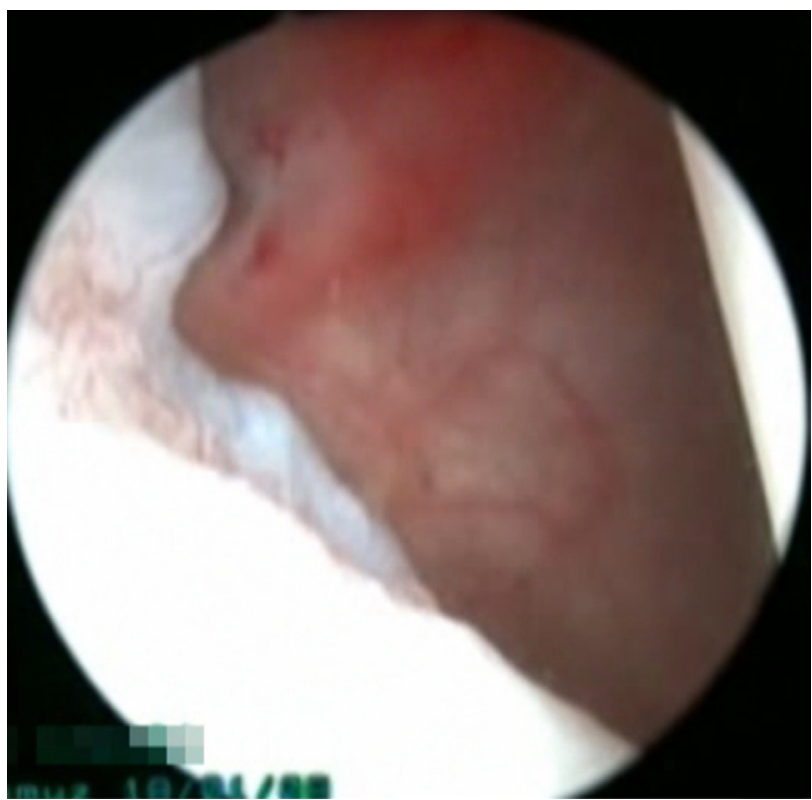

Şekil 4. Genişlemiş kapsül.

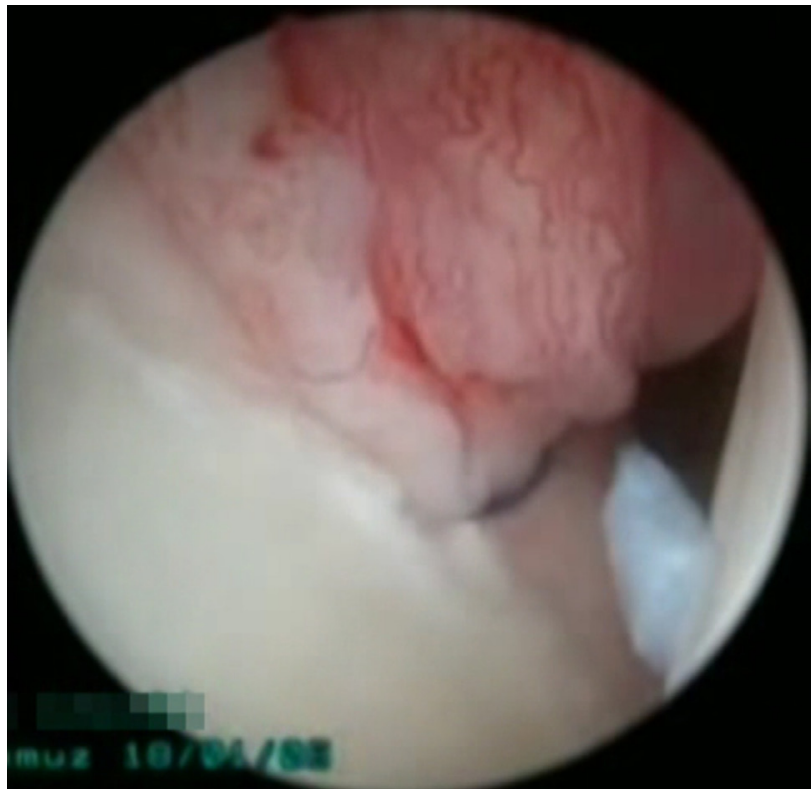

Şekil 6. Kapsülü labruma dikerek pilikasyon.

Artroskopik değerlendirmede sadece kapsüler gevşeklik varsa kapsülün labruma pilike edilerek dikilmesi ve omuz içindeki yumuşak doku dengesi sağlanmalıdır. Denge bazen hem posterior hem de anteriorden plikasyon ile sağlanır (Şekil 3-6).

Labrum posterior dudaktan ayrılmış ise tiftikli uçlar temizlendikten sonra posteriora iki veya üç kemik çıpası yardımı ile tespit edilir. Anteior labrum tamirindeki yöntem ve araçlar kullanılır; posterior Bankart tamiri olarak da isimlendirilir (Şekil 7-9). 


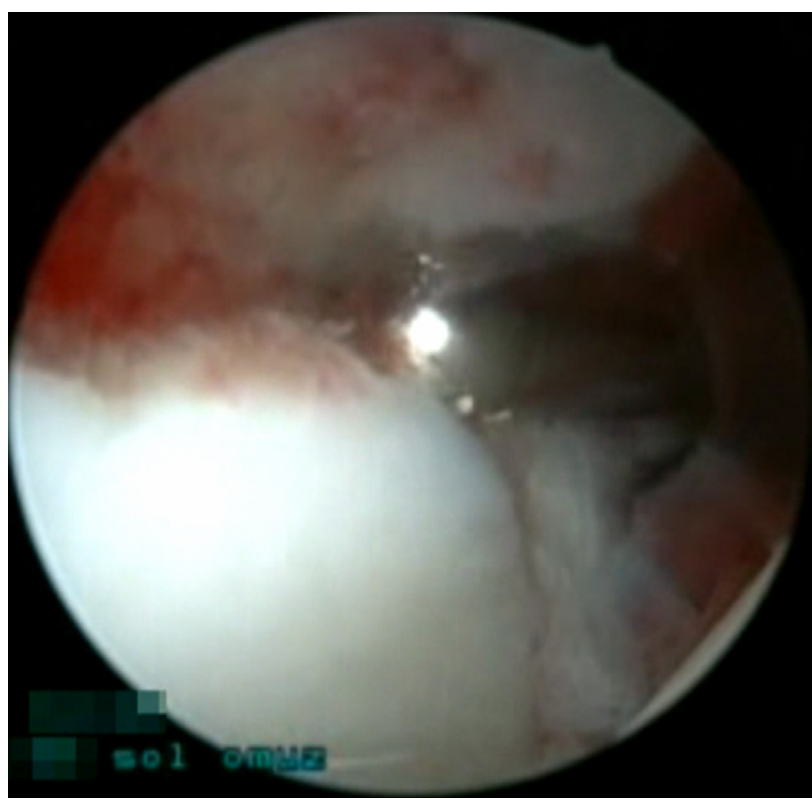

Şekil 7. Posterior glenoid debridmanı.

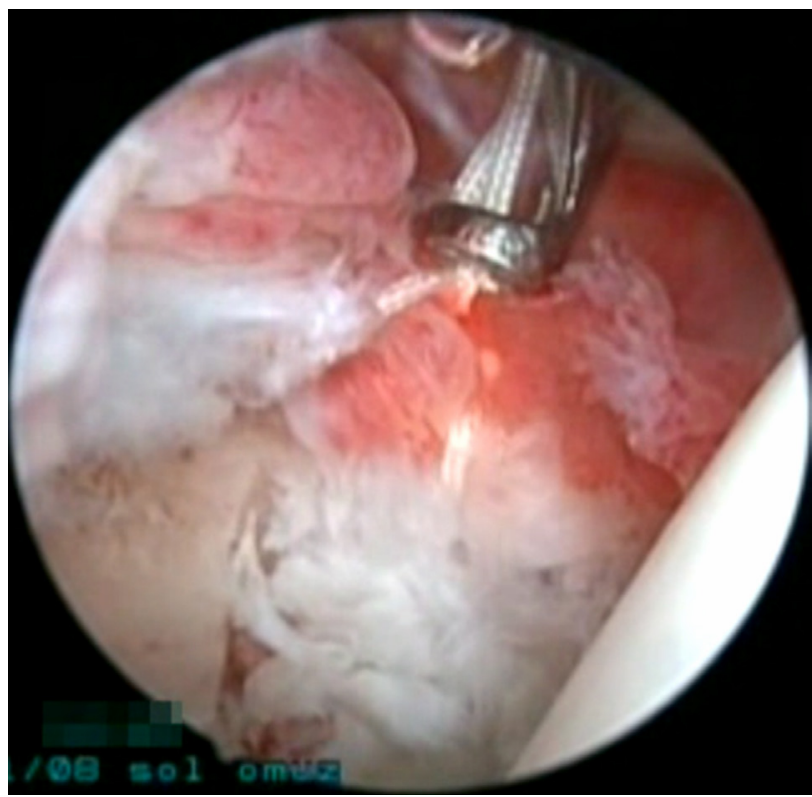

Şekil 9. Labrum ve kapsülün posterior glenoide kemik çıpası ile tespiti.

\section{KAYNAKLAR}

1. Antoniou J, Harryman DT 2nd. Posterior instability. Orthop Clin North Am 2001;32(3):463-73, ix.

2. Abrams JS, Bradley JP, Angelo RL, Burks R. Arthroscopic management of shoulder instabilities: anterior, posterior, and multidirectional. Instr Course Lect 2010;59:141-55.

3. Van Tongel A, Karelse A, Berghs B, Verdonk R, De Wilde L. Posterior shoulder instability: current concepts review. Knee Surg Sports Traumatol Arthrosc 2011;19(9):1547-53. CrossRef

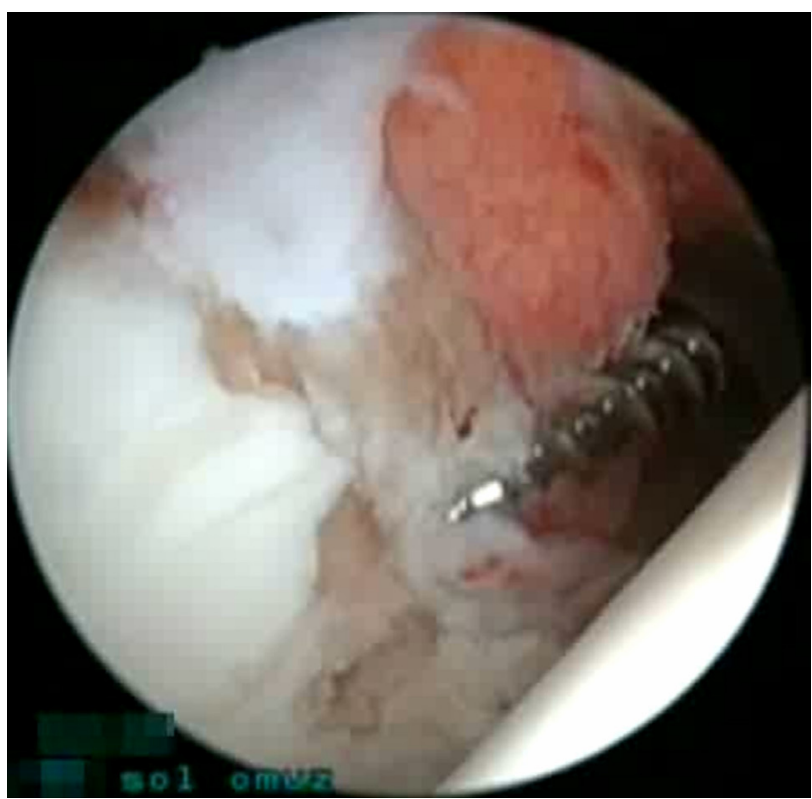

Şekil 8. Posterior glenoid dudağa kemik çıpası yerleştirilmesi.

4. Provencher MT, LeClere LE, King S, McDonald LS, Frank RM, Mologne TS, Ghodadra NS, Romeo AA. Posterior instability of the shoulder: diagnosis and management. Am J Sports Med 2011;39(4):874-86. CrossRef

5. Fuchs B, Jost B, Gerber C. Posterior-inferior capsular shift for the treatment of recurrent, voluntary posterior subluxation of the shoulder. J Bone Joint Surg Am 2000;82(1):16-25.

6. Gerber C, Ganz R, Vinh TS. Glenoplasty for recurrent posterior shoulder instability. An anatomic reappraisal. Clin Orthop Relat Res 1987;(216):70-9.

7. Provencher MT, Romeo AA. Posterior and multidirectional instability of the shoulder: challenges associated with diagnosis and management. Instr Course Lect 2008;57:133-52.

8. Shin RD, Polatsch DB, Rokito AS, Zuckerman JD. Posterior capsulorrhaphy for treatment of recurrent posterior glenohumeral instability. Bull Hosp Jt Dis 2005;63(1-2):9-12.

9. Bigliani LU, Pollock RG, Mcllveen SJ, Endrizzi DP, Flatow EL. Shift of the posteroinferior aspect of the capsule for recurrent posterior glenohumeral instability. J Bone Joint Surg Am 1995;77(7):1011-20.

10. Shah N, Tung GA. Imaging signs of posterior glenohumeral instability. AJR Am J Roentgenol 2009;192(3):730-5. CrossRef

11. Robinson CM, Seah M, Akhtar MA. The epidemiology, risk of recurrence, and functional outcome after an acute traumatic posterior dislocation of the shoulder. J Bone Joint Surg Am 2011;93(17):1605-13. CrossRef

12. Tibone JE, Bradley JP. The treatment of posterior subluxation in athletes. Clin Orthop Relat Res 1993;(291):124-37.

13. Millett PJ, Clavert P, Hatch GF 3rd, Warner JJ. Recurrent posterior shoulder instability. J Am Acad Orthop Surg 2006;14(8):464-76.

14. Hawkins RJ, Janda DH. Posterior instability of the glenohumeral joint. A technique of repair. Am J Sports Med 1996;24(3):275-8.

15. Tibone JE. Posterior capsulorrhaphy for posterior shoulder subluxation. Techniques in Orthopaedics 1989;3(4):46-50. 
16. Pollock RG, Bigliani LU. Recurrent posterior shoulder instability. Clin Orthop Relat Res 1993;(291):85-96.

17. Mowery CA, Garfin SR, Booth RE, Rothman RH. Recurrent posterior dislocation of the shoulder: treatment using a bone block. J Bone Joint Surg 1985;67(5):777-81.

18. Boyd HB, Sisk TD. Recurrent posterior dislocation of the shoulder. J Bone Joint Surg Am 1972;54(4):779-86.

19. Kakar S, Voloshin I, Kaye EK, Crivello K, Edgar CM, Edmond CM, Pryor JD, Schepsis AA. Posterior shoulder instability: comprehensive analysis of open and arthroscopic approaches. Am J Orthop (Belle Mead NJ) 2007;36(12):655-9.
20. McLaughlin HL. Posterior dislocation of the shoulder. J Bone Joint Surg Am 1952;24-A-3:584-90.

21. Lichtenberg S, Habermeyer P. Open and arthroscopic procedures for posterior shoulder instability. Orthopade 2009;38(1):54-63. CrossRef

22. Bradley JP, Forsythe B, Mascarenhas R. Arthroscopic management of posterior sisshoulder instability: diagno, indications, and technique. Clin Sports Med 2008;27(4):64970. CrossRef

23. Akpinar S, Uysal M, Ozkoç G, Tandoğan NR. Thermal assisted arthroscopic stabilization of unstable shoulder. Acta Orthop Traumatol Turc 2005;39 Suppl 1:96-102. 